\title{
The frequency and nature of incidental findings in large-field cone beam computed tomography scans of an orthodontic sample
}

\author{
Ryan Edwards ${ }^{1 *}$, Noura Alsufyani ${ }^{2}$, Giseon Heo ${ }^{1}$ and Carlos Flores-Mir ${ }^{1}$
}

\begin{abstract}
Background: The aim of this study is to evaluate the nature and frequency of incidental findings in large-field maxillofacial cone beam computed tomography (CBCT).

Methods: A total of 427 consecutive $C B C T$ radiologic reports obtained for orthodontic purposes were retrospectively reviewed. Findings were summarized and categorized into six anatomic categories.

Results: A total of 842 incidental findings were reported in the 427 CBCT scans (1.97 findings/scan). The most prevalent findings were those located in the airway (42.3\%), followed by the paranasal sinuses (30.9\%), dentoalveolar (14.7\%), surrounding hard/soft tissues (4.0\%), temporomandibular joint (TMJ) (6.4\%), and cervical vertebrae (1.3\%) regions. Non-odontogenic findings, defined as those located outside the dentition and associated alveolus, represented 718 of the 842 (85.3\%) findings.

Conclusions: This study confirms the high occurrence of incidental findings in large-field maxillofacial CBCT scans in a sample of orthodontically referred cases. The majority are extragnathic findings, which can be normally considered outside the regions of interest of many dental clinicians. Specifically, incidental findings in the naso-oropharyngeal and paranasal air sinuses are the most frequent. This underscores the need for comprehensive review of the entire data volume and the requisite to properly document all findings, regardless of the region of interest.
\end{abstract}

Keywords: Cone beam computed tomography; Incidental findings; Maxillofacial region

\section{Background}

Cone beam computed tomography (CBCT) has been rapidly integrating into the field of dentistry to produce three-dimensional (3-D) imaging of the craniofacial complex. Current applications include, but are not limited to, specific orthodontic diagnosis, evaluation of the temporomandibular joint (TMJ), visualization of impacted teeth, evaluation of root resorption, preoperative implant planning, upper airway analysis, and presurgical treatment planning for both orthognathic surgery and craniofacial/ cleft lip and palate cases [1-10].

When compared with conventional 2-D imaging, CBCT captures a much larger field of view. As such, there is an increased potential to identify incidental findings (IFs). IFs

\footnotetext{
* Correspondence: dr.ryanedwards@gmail.com

'Orthodontic Graduate Program, Faculty of Medicine and Dentistry, University of Alberta, Edmonton, Alberta T6G 2R3, Canada

Full list of author information is available at the end of the article
}

are defined as any and all discovered findings, detected by $\mathrm{CT}, \mathrm{MRI}, \mathrm{CBCT}$, or any other imaging modalities that are unrelated to the clinical indication for the imaging being performed [11]. Arguably, as important as the detection is the action that each unexpected finding invokes, in terms of deciding the necessity for further evaluation and/or management [12]. As a large majority of IFs detected in CBCT imaging are extragnathic [13], the dental clinician may be unfamiliar with interpretation of anatomical structures outside the primary region of interest [14]. As such, the European Academy of Dento-MaxilloFacial Radiology (EADMFR) and the American Academy of Oral and Maxillofacial Radiology (AAOMR) outline that if the interpreting clinician is not highly experienced in $\mathrm{CBCT}$ interpretation, appropriate referral is required to an oral and maxillofacial radiologist (OMFR) for review and that the entire volume must be interpreted regardless of the region of interest $[15,16]$. 
A number of studies in the literature have investigated the frequency of IFs in CBCT imaging in various patient samples [14,17-23]. Of these, only two have investigated an orthodontic sample exclusively $[17,20]$. Thus, additional studies are required to further define the nature of IFs in CBCT imaging in order to provide an accurate estimation of potential findings and pathologies, specifically in orthodontic patients. This descriptive study aims to assess the type, frequency, and location of incidental findings in large-field maxillofacial CBCT imaging, collected retrospectively via radiologic reports from an orthodontic sample.

\section{Methods}

From a private diagnostic imaging center, 427 consecutive patients were retrospectively evaluated via chart review. No sample size calculations were performed. Instead, the chosen sample was deemed appropriate in size by comparison with similar studies in the literature. All patients received a single large field-of-view CBCT scan between the dates of 21 April 2011 and 21 May 2013, for the purpose of comprehensive diagnostic orthodontic records. All scans were acquired using an i-CAT Next Generation machine (Imaging Sciences International, Hatfield, PA, USA). Ethics approval for the retrospective chart review was obtained from the University of Alberta Health Research Ethics Board - Health Panel.

The kilovoltage $(\mathrm{kV})$ and milliamperage $(\mathrm{mA})$ were fixed $(120 \mathrm{kV}, 5 \mathrm{~mA})$, but volume height, imaging time, and reconstruction voxel size varied slightly. All scans were acquired using a large field of view, which extended from the roof of the orbits inferiorly to at least the second cervical vertebrae. The voxel size ranged from 0.2 to $0.3 \mathrm{~mm}$, with the vast majority (97.2\% of scans) using a voxel size of $0.3 \mathrm{~mm}$. The time of exposure for the scans was $4.8 \mathrm{~s}$ for 195 subjects, $8.9 \mathrm{~s}$ for 215 subjects, and $26.9 \mathrm{~s}$ for 17 subjects, after acquiring the scout image.

Following comprehensive interpretation of each scan by a single, board-certified oral maxillofacial radiologist, the same OMFR generated written radiologic reports for each image. All scans were reviewed by the OMFR using the imaging software InVivoDental 5.0 (Anatomage, San Jose, CA, USA). If the OMFR had any uncertainties or doubts regarding any of the findings, other OMFRs were contacted to seek a consensus-based opinion. The radiology reports followed a consistent format and contained a listing of all radiographic findings, which were used to tabulate the data in this study. If an additional reason for imaging was indicated (ie., investigation of a clinically detected impacted cuspid), the specific finding(s) was/ were not considered as incidental. The subject's charts were not reviewed for any coincidence between systemic conditions and the findings. The radiologist was considered blinded to the objective of the present study, as at the time the radiologic reports were generated, it was not apparent that this data would be collected retrospectively for analysis.

A single researcher (RE), not associated with the imaging center, retrospectively reviewed the radiologic reports and tabulated all findings for descriptive analysis by entering data into formulated tables using Microsoft Excel. Decisions regarding the placement of the individual findings into the specific anatomic categories were performed via consensus of three researchers. If a subject had more than one finding for any given anatomic region, the total number of findings was recorded. For example, if a subject had both adenoid hyperplasia and concha bullosa, both were recorded as airway findings. The absence of third molars was not included as an incidental finding, as these teeth are commonly missing [24] or may have been previously extracted.

The complete data collection process was repeated by the single researcher, separated by a 60 -day period. Intraexaminer agreement was assessed using the kappa statistic. Both age and sex of the patients were collected. Using a Bonferroni corrected $\alpha$ of $0.008(0.05 / 6)$, a series of logistic regression analyses were performed to investigate if for any given age, the odds of identifying an incidental finding was different between sexes, for any of the six individual anatomic regions.

\section{Results}

Of the 427 subjects, 180 (42.2\%) were males and 247 $(57.8 \%)$ were females. The age of the patients who received scans ranged from 5 to 46 years; the mean age was $14.2( \pm 6.3)$ years and the median age was 12.0 years. The sample was divided into four age categories, aimed at representing subjects in the primary to early mixed dentition ( $<7$ years), mid-mixed to early permanent dentition ( 8 to 11 years), adolescents in the permanent dentition (12 to 17 years), and adults ( $>17$ years). The distribution of the total sample by age can be viewed in Figure 1.

All findings were categorized and placed into one of six common subgroups based on anatomic region. The groupings created for analysis were dentoalveolar, nasooropharyngeal airway, paranasal sinuses, temporomandibular joint, cervical vertebrae, and surrounding hard/ soft tissue. The groupings and frequency of individual findings can be viewed in Table 1 and Figure 2. With the exception of 23 patients in whom further investigation of suspected impacted canines was indicated in the clinical referral, no other additional clinical, radiographic, or histological information was used. For these 23 patients, the impacted canines were not included as incidental findings.

A total of 842 incidental findings were identified in 356 of the 427 scans $(83.4 \%)$, representing an overall rate 


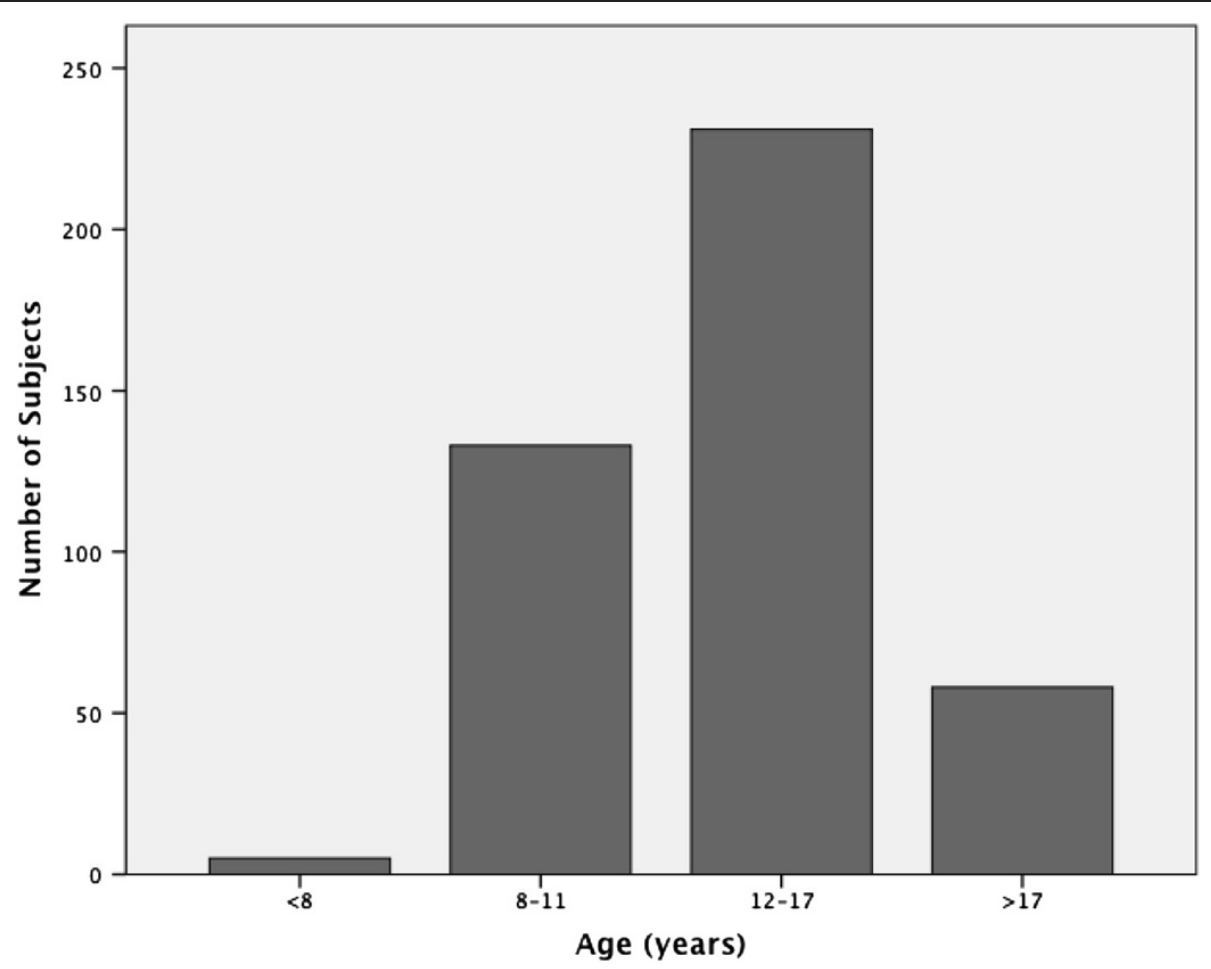

Figure 1 Age distribution of orthodontic sample.

of 1.97 incidental findings per scan. The most common number of incidental findings per scan was 2 , which occurred in 117 of 427 scans (Table 2). Non-odontogenic findings, defined as those located outside the dentition and associated alveolus, represented 718 of the 842 (85.3\%) findings.

The most frequently identified incidental findings were those located in the naso-oropharyngeal airway, representing $42.3 \%$ of all findings. The second most common form of incidental findings was those identified in the paranasal air sinuses, representing $30.9 \%$ of all findings. Dentoalveolar findings represented $14.7 \%$, while TMJ findings represented $6.4 \%$ of all incidental findings. Findings in the surrounding hard/soft tissues and cervical vertebrae represented $4.0 \%$ and $1.3 \%$, respectively.

The kappa score measuring the level of inter-examiner agreement in the data collection was 1.0, indicating perfect agreement. The results of the logistic regression analysis suggest that when controlling for age, only one anatomic category demonstrated statistically significant differences between males and females (Table 3), where females were 2.55 times $(P<0.001,95 \%$ CI $[1.29,5.03])$ more likely to have a TMJ finding than men.

Further follow-up was specifically suggested by the interpreting OMFR for the following seven findings:

1. Polypoidal soft tissue mass on the superior surface of soft palate (Figure 3)
2. An irregular thickening of the nasal cavity; nasal polyps cannot be ruled out (Figure 4)

3. Severe adenoid hypertrophy affecting patency of nasopharyngeal airway (Figure 5)

4. Complete obliteration of maxillary, sphenoid, frontal, and ethmoid sinuses with soft tissue/mucosal-like density (Figure 6)

5. Enlarged sella turcica (Figure 7)

6. Odontogenic cyst pericoronal to tooth 48 (Figure 8)

7. Soft tissue asymmetry with enlargement of the left-side pharynx and larynx (Figure 9)

\section{Discussion}

CBCT imaging is increasingly being utilized in diagnosis and treatment planning in orthodontics. In this study, 427 consecutive CBCT radiologic reports of orthodontic patients were retrospectively reviewed from a private diagnostic imaging center. Reported findings include developmental findings, normal anatomic variants, agerelated findings, and pathological findings. As mentioned in a previous systematic review [13], at least two methods for reporting the incidence of incidental findings are described in the literature: (i) by describing the absolute number of IFs detected or (ii) describing the number of CBCT scans that contain IFs. The former method, using the absolute number of IFs, is favored because it is highly likely for multiple IFs to be detected in a single CBCT scan; our results confirm this. 
Table 1 Frequency of incidental of findings among the 6 designated anatomic regions

\begin{tabular}{|c|c|c|}
\hline Incidental finding category & $\begin{array}{l}\text { Frequency } \\
(n)\end{array}$ & $\begin{array}{l}\text { Percentage } \\
\text { of IFs }\end{array}$ \\
\hline Cervical vertebrae & 11 & 1.3 \\
\hline Cervical vertebrae fusion & 5 & 0.59 \\
\hline Cervical vertebral flattening & 1 & 0.12 \\
\hline Cervical osteoarthritis & 1 & 0.12 \\
\hline $\begin{array}{l}\text { Mediolateral rotation (to } \mathrm{L} \text { ) of } \mathrm{C} 2-\mathrm{C} 3 \text { in } \\
\text { relation to } \mathrm{C} 1\end{array}$ & 1 & 0.12 \\
\hline Bony ossicle in $\mathrm{C} 1-\mathrm{C} 2$ region & 1 & 0.12 \\
\hline Posterior ponticle of $\mathrm{C} 1$ & 2 & 0.24 \\
\hline Dentoalveolar & 124 & 14.7 \\
\hline Supernumerary & 6 & 0.71 \\
\hline Hypodontia (excluding third molars) & 37 & 4.39 \\
\hline Microdontia & 4 & 0.48 \\
\hline Impactions & 28 & 3.33 \\
\hline Enamel pearl & 1 & 0.12 \\
\hline Gemination & 1 & 0.12 \\
\hline Retained primary tooth/fragment & 6 & 0.71 \\
\hline Dilaceration & 1 & 0.12 \\
\hline Severe root shortening (localized) & 1 & 0.12 \\
\hline Ectopic position & 2 & 0.24 \\
\hline Idiopathic osteosclerosis (DBI) & 16 & 1.90 \\
\hline Odontogenic cyst & 1 & 0.12 \\
\hline Simple bone cyst & 2 & 0.24 \\
\hline Buccal bifurcation cyst & 1 & 0.12 \\
\hline Torus mandibularis & 1 & 0.12 \\
\hline Periapical cemento-ossesous dysplasia & 2 & 0.24 \\
\hline External root resorption & 5 & 0.59 \\
\hline Periapical rarefying osteitis & 8 & 0.95 \\
\hline Periapical sclerosing osteitis & 1 & 0.12 \\
\hline Naso-oropharyngeal airway & 356 & 42.3 \\
\hline Choanal-retrochoanal polyp & 1 & 0.12 \\
\hline Meatal obliteration & 1 & 0.12 \\
\hline Adenoid hypertrophy & 154 & 18.3 \\
\hline Lingual tonsil hypertrophy & 55 & 6.53 \\
\hline Palatine tonsil hypertrophy & 8 & 0.95 \\
\hline Concha bullosa & 30 & 3.56 \\
\hline Nasal mucosal thickening; rhinitis & 25 & 2.97 \\
\hline Nasal septal deviation & 45 & 5.34 \\
\hline Nasal septal deviation (with bone spur) & 22 & 2.61 \\
\hline Turbinate hypertrophy & 5 & 0.59 \\
\hline Nasal polyps & 1 & 0.12 \\
\hline $\begin{array}{l}\text { Irregular soft tissue border of naso- } \\
\text { oropharynx }\end{array}$ & 2 & 0.24 \\
\hline Dystrophic calcification of tonsils & 5 & 0.59 \\
\hline
\end{tabular}

Table 1 Frequency of incidental of findings among the 6 designated anatomic regions (Continued)

\begin{tabular}{|c|c|c|}
\hline Concha enlargement & 1 & 0.12 \\
\hline $\begin{array}{l}\text { Opacification of the middle and superior } \\
\text { nasal meatuses }\end{array}$ & 1 & 0.12 \\
\hline Paranasal sinuses & 260 & 30.9 \\
\hline $\begin{array}{l}\text { Localized inflammatory conditions } \\
\text { (mucositis-sinusitis) }\end{array}$ & 152 & 18.1 \\
\hline Pansinusitis & 11 & 1.31 \\
\hline Ostia blockage & 11 & 1.31 \\
\hline Retention pseudocyst & 58 & 6.89 \\
\hline Sinus hypoplasia & 14 & 1.66 \\
\hline Sinus pnuematization & 11 & 1.31 \\
\hline Sinus aplasia & 1 & 0.12 \\
\hline Accessory ostia & 1 & 0.12 \\
\hline Antrolith & 1 & 0.12 \\
\hline Surrounding soft/hard tissues & 34 & 4.0 \\
\hline Osteoma & 1 & 0.12 \\
\hline Fibrous dysplasia & 5 & 0.59 \\
\hline Jugular bulb pseudolesion & 4 & 0.48 \\
\hline Pnuematization of mastoid air cells & 12 & 1.43 \\
\hline Enlarged sella turcica & 3 & 0.36 \\
\hline Soft tissue polyp & 1 & 0.12 \\
\hline Ventriculoperitoneal shunt & 1 & 0.12 \\
\hline Pineal gland calcification & 1 & 0.12 \\
\hline Osteoma cutis & 1 & 0.12 \\
\hline Calcified stylohyoid ligament & 2 & 0.24 \\
\hline Dystrophic calcification of lymph node & 1 & 0.12 \\
\hline Enlarged incisive (naso-palatine) canal & 1 & 0.12 \\
\hline $\begin{array}{l}\text { Depression/notch along the anterior } \\
\text { surface of clivus }\end{array}$ & 1 & 0.12 \\
\hline Temporomandibular joint & 54 & 6.4 \\
\hline Condylar hypoplasia & 16 & 1.90 \\
\hline $\begin{array}{l}\text { Physiologic remodeling (flat margins, } \\
\text { subchondral sclerosis) }\end{array}$ & 19 & 2.26 \\
\hline $\begin{array}{l}\text { Degenerative changes (osteophytes, } \\
\text { erosions) }\end{array}$ & 18 & 2.14 \\
\hline Bifid condyle & 1 & 0.12 \\
\hline
\end{tabular}

From our sample of orthodontic patients, a total of 842 IFs were identified in the 427 scans, representing an overall rate of 1.97 IFs per scan. It is known that the frequency of IFs in CBCT imaging varies among studies in the literature, ranging from 1.1 to 2.9 IFs per CBCT scan [14,17-21]. The IF rate reported from our sample is thus similar to that of other studies. At least one IF was identified in 356 of 427 scans (83.4\%), which is also similar to that of other studies in the literature, which report the number of CBCT scans containing at least one IF to be between $90.7 \%$ and $94.3 \%[14,18,21,23]$. However, in 


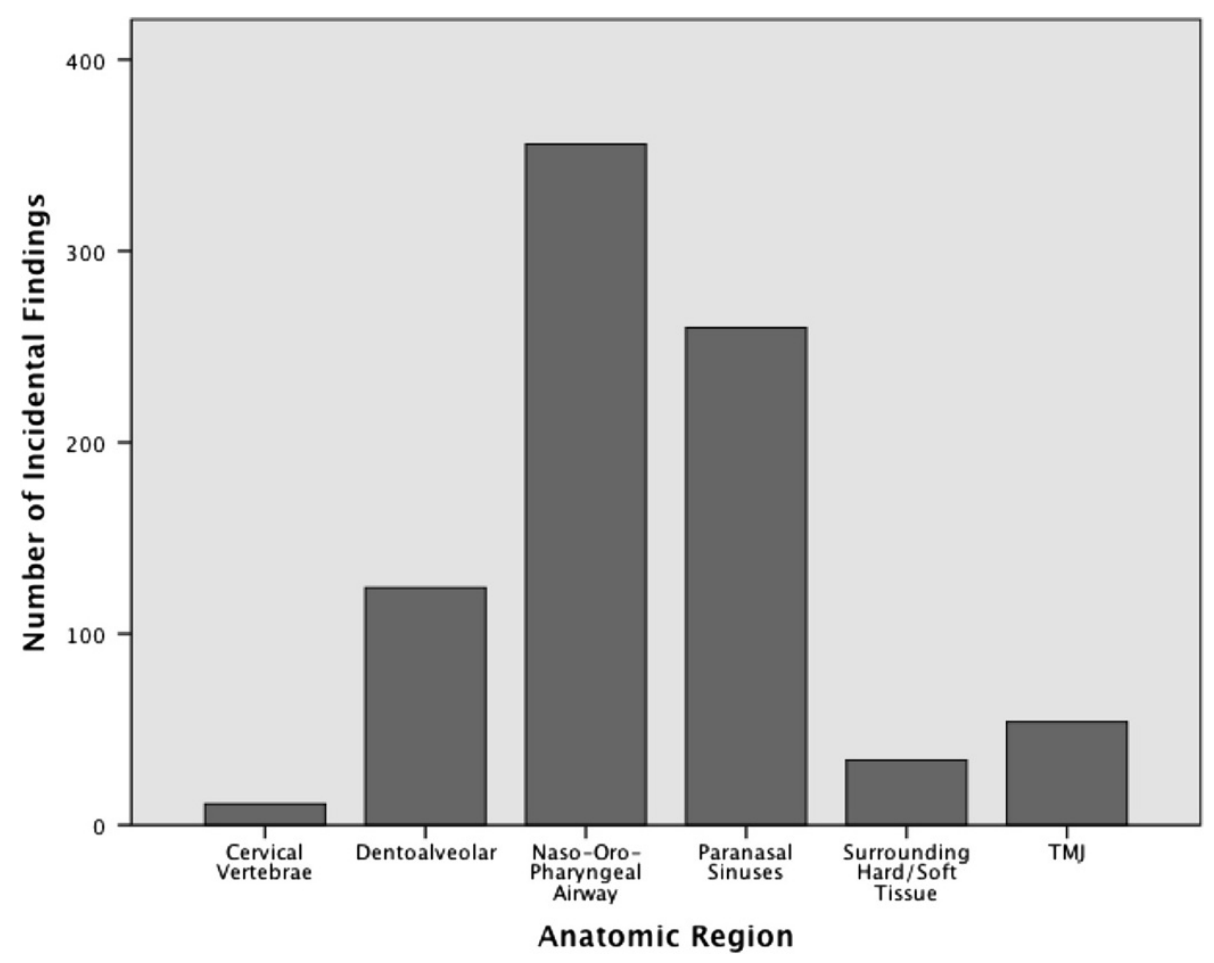

Figure 2 Distribution of incidental findings among the six designated anatomic regions.

studies by Rheem et al. [22], Pliska et al. [17], Rheem et al. [22], and Cha et al. [19], it was respectively reported that IFs were identified in only $66 \%, 65.5 \%, 40.1 \%$, and $24.5 \%$ of CBCT scans, which is significantly less than in our sample. These observed variations in the literature can likely be attributed to differences in the samples, such as age groups; in radiologist's reporting styles; and in the definition of the term incidental finding.

\section{Naso-oropharyngeal airway}

The most common location for identified IFs was in the nasal-oropharyngeal airway, representing $42.3 \%$ of all findings, with adenoid hyperplasia (18.3\%), nasal septal

\section{Table 2 Incidental finding frequency categorized by} number

\begin{tabular}{ccc}
\hline Number of incidental findings & Frequency $(\boldsymbol{n})$ & Percentage of total \\
\hline 0 & 71 & 16.6 \\
1 & 109 & 25.5 \\
2 & 117 & 27.4 \\
3 & 65 & 15.2 \\
4 & 34 & 8.0 \\
5 & 21 & 4.9 \\
6 & 8 & 1.9 \\
7 & 1 & 0.2 \\
8 & 1 & 0.2 \\
\hline
\end{tabular}

deviations (8.0\%), and lingual tonsil hyperplasia (6.5\%) identified most frequently. This high rate of airway findings is consistent with the literature, as various other $\mathrm{CBCT}$ studies have demonstrated that airway findings represent $8.4 \%$ to $35.0 \%$ of total CBCT findings $[14,17-19,21,23]$.

Septal deviations represented $8.0 \%$ of findings in our sample, which is less than the $19.4 \%$ reported by Smith et al. [25]. Concha bullosa, a common anatomical variation of the sino-nasal anatomy characterized by pneumatization of the nasal turbinates, represented $3.6 \%$ of findings. This is much less than other reports in the literature, in which the prevalence of concha bullosa varied from $35 \%$ to $68 \%$ [25-28]. The joint incidence of septal deviation and concha bullosa has been previously reported to be high (19.5\% to $44.6 \%)$ [25,29]. In our sample, of the

Table $3 P$ values obtained from a series of logistic regression analyses for each of the six anatomic regions

\begin{tabular}{lc}
\hline Anatomic region & Sex $(\boldsymbol{P}$ value $)$ \\
\hline Dentoalveolar & 0.447 \\
Naso-oropharyngeal airway & 0.556 \\
Paranasal sinus & 0.416 \\
Temporomandibular joints & $<0.001$ \\
Surrounding hard/soft tissues & 0.144 \\
Cervical vertebrae & 0.808 \\
\hline
\end{tabular}




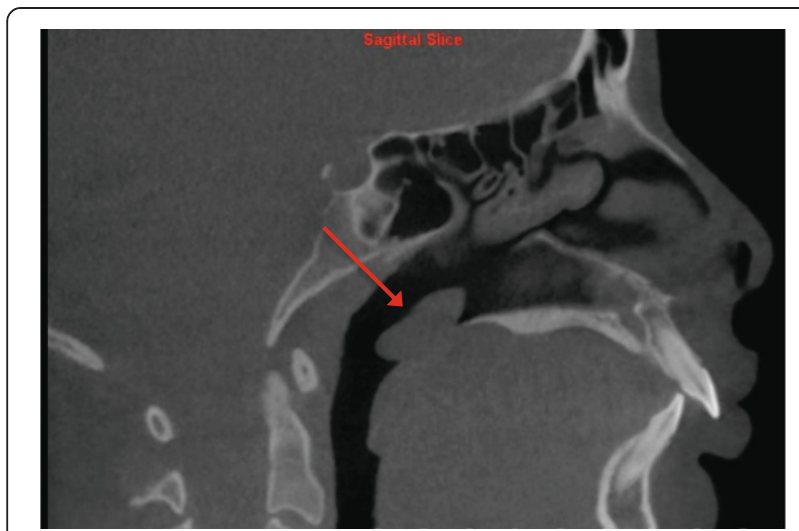

Figure 3 Polypoidal soft tissue mass on superior surface of soft palate as viewed on sagittal slice.

30 findings of concha bullosa, septal deviations were also identified in nine of these subjects (30\%).

The majority (25.8\%) of upper airway findings in our sample were due to varying forms of adeno-tonsillar hypertrophy, specifically adenoid/pharyngeal (18.3\%), lingual (6.5\%), and palatal tonsil (0.1\%) hypertrophy. Upper airway obstruction has been described as a possible environmental cause of malocclusion and disharmonious dento-facial development observed in growing subjects [30-32]. Various studies have discussed the contributing

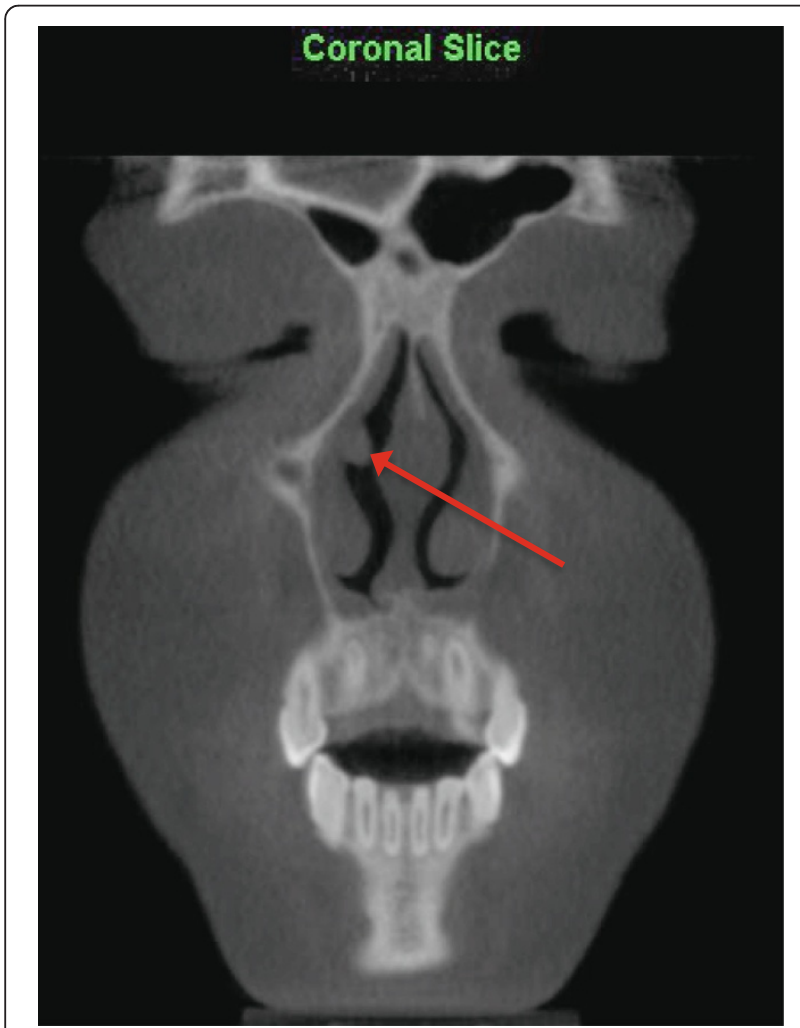

Figure 4 An irregular thickening of the nasal cavity as viewed on coronal slice.

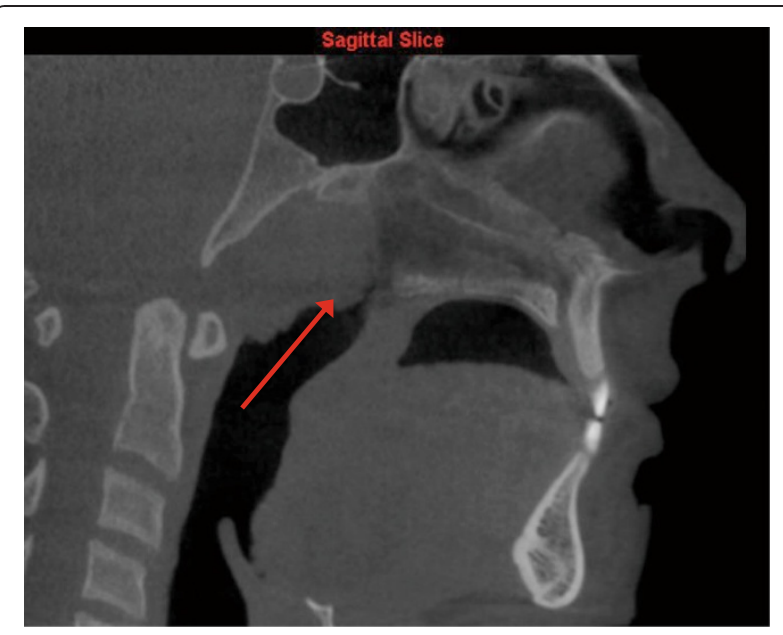

Figure 5 Severe adenoid hypertrophy affecting patency of the nasopharyngeal airway as viewed on sagittal slice.

role of not only adeno-tonsillar hypertrophy [33-35], but also nasal septum deviation [35,36], allergic rhinitis [37], and inferior turbinate hypertrophy [38,39] in partial upper airway obstruction.

The high frequency of airway findings in our sample demonstrates that $\mathrm{CBCT}$ can be an important tool in screening for airway abnormalities. However, the current reference standard for assessing the nasal cavity and nasopharynx remains nasoendoscopy (NE) [40]. An important distinction must be made between identifying potential upper airway constriction in $\mathrm{CBCT}$ imaging and relating it to the actual presence and/or severity of clinical obstruction. Specifically regarding adenoid size, it has been demonstrated in a recent study that $\mathrm{CBCT}$ imaging demonstrated excellent sensitivity (88\%) and specificity (93\%) when compared with NE [41]. In addition, the assessment of adenoid size using CBCT had strong accuracy (intra-class coefficient $(\mathrm{ICC})=0.80,95 \% \mathrm{CI} \pm 0.15)$ and very good inter-rater $(\mathrm{ICC}=0.85,95 \% \mathrm{CI} \pm 0.08)$ and intra-rater reliability ( $\mathrm{ICC}=0.84,95 \% \mathrm{CI} \pm 0.08)$ among subjects. This suggests that CBCT can be a reliable and accurate tool for identifying adenoid enlargement. Similar studies should be conducted to investigate the sensitivity and specificity of CBCT compared to $\mathrm{NE}$ in regard to other airway findings, such as septal deviation and turbinate hypertrophy.

Despite the validation of CBCT for adenoid assessment, management decisions should be made on the basis of clinical history and NE, rather than entirely on radiologic findings [42]. Furthermore, CBCT imaging should never be considered a replacement to NE. However, when available because it was indicated for other reasons, this imaging technology does provide orthodontic clinicians with an accurate and reliable tool for the assessment of adenoid size, facilitating screening for and early 

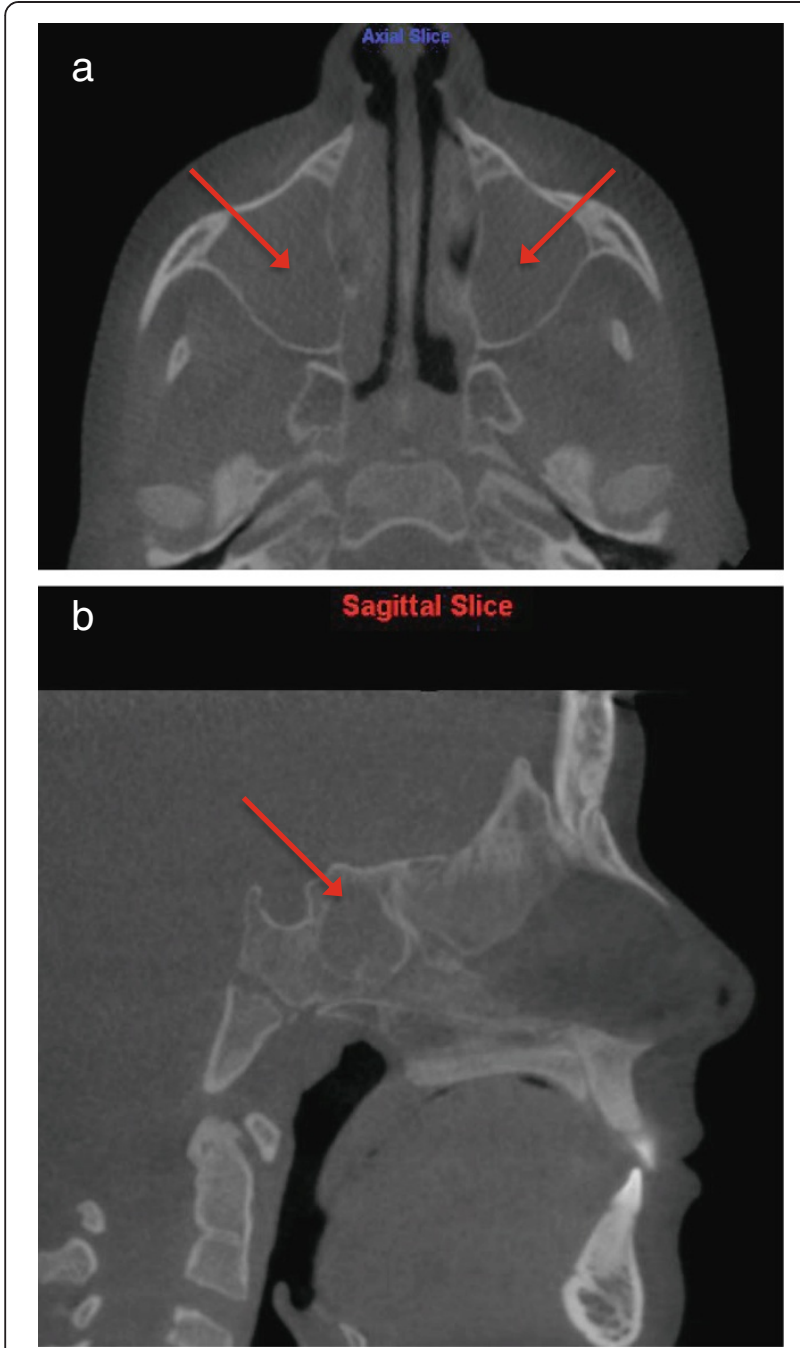

Figure 6 Complete obliteration of maxillary, sphenoid, frontal, and ethmoid sinuses with soft tissue/mucosal-like density.

Viewed on (a) axial and (b) sagittal slices.

detection of adenoid enlargement and other potential airway problems [41].

\section{Paranasal air sinus region}

Paranasal sinus changes represented $30.9 \%$ of all findings in our sample, which is similar to other CBCT studies, in which sinus changes have been commonly demonstrated ranging from $23.9 \%$ to $62.6 \%$ of findings $[14,18,20,21,43]$. Many studies using MRI and medical CT imaging also confirm a high prevalence of incidental sinus findings. Havas et al. [44], using CT, reported changes in one or more paranasal sinuses in up to $42.5 \%$ of asymptomatic patients. Diament et al. [45] identified maxillary and ethmoid sinus opacifications in $50 \%$ of a pediatric sample referred for cranial CT. Lim et al. [46] and Gordts et al. [47]



Figure 7 Enlarged sella turcica as viewed on sagittal slice.

respectively reported that $32.3 \%$ and $45 \%$ of pediatric subjects have sinus abnormalities in non-ENT MRI imaging.

Localized inflammatory conditions consisting of mucositis-sinusitis (18.1\%) and retention psuedocysts (6.89\%) were the most frequently identified sinus findings. Concerning sinus mucosal inflammation in $\mathrm{CBCT}$ imaging, it is known from the literature that it is a common finding identified in $15.0 \%$ to $55.1 \%$ of patients $[14,18,20-23,48]$. For the purposes of this study, sinusitis was defined as the radiographically detectable thickening of the sinus mucosa. Findings were based entirely on radiographic appearance, as no clinical

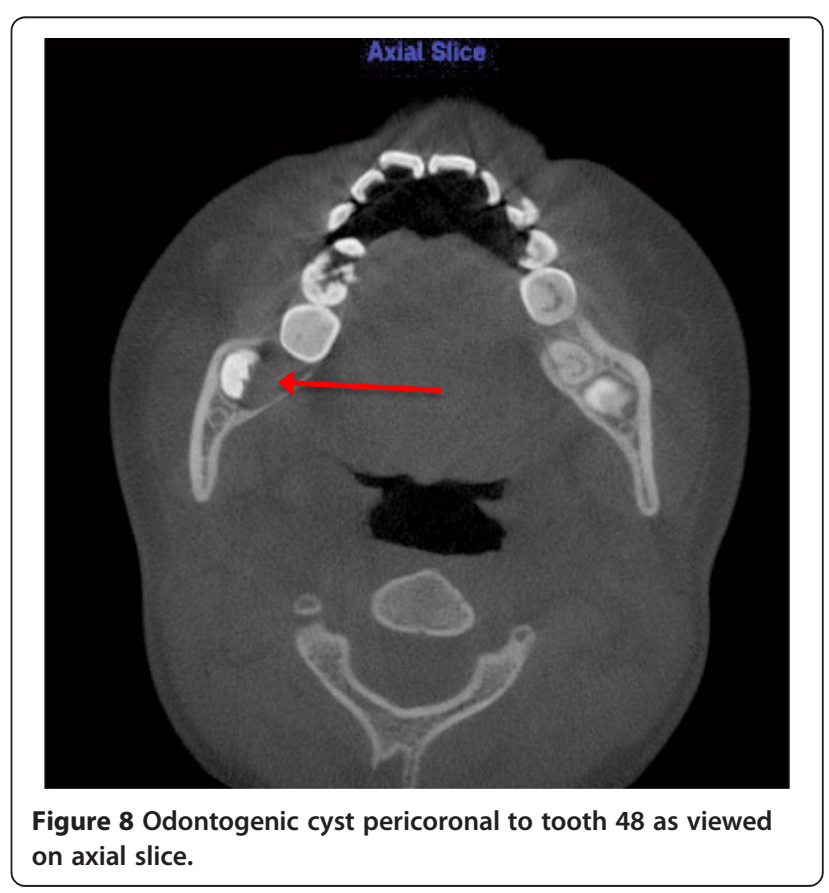






Figure 9 Soft tissue asymmetry with thickening and enlargement of left-side pharynx and larynx as viewed on axial slice.

information was assessed. Pansinusitis, an inflammation of all the paranasal sinuses, was present in 11 subjects, representing $1.31 \%$ of findings. In 10 of 11 pansinusitis patients, other concomitant airway findings were also reported, including adenoid hypertrophy (six subjects), blocked ostia (two subjects), and maxillary sinus hypoplasia (two subjects). Maxillary mucous retention pseudocysts are identified as incidental findings in $2.9 \%$ to $16.4 \%$ of CBCT scans $[14,17,20,23]$. They usually spontaneously regress or show no significant change in size over the long term and rarely lead to symptoms [49]. It is suggested that in the absence of associated complications, conservative monitoring is the appropriate management strategy.

In evaluating maxillary sinus abnormalities using 2-D panoramic imaging, Vallo et al. [50] identified mucosal thickening in $12 \%$ and mucous retention cysts in $7 \%$ of radiographs. Bondemark et al. [51] identified sinus mucosal thickening in $26.8 \%$ of panoramic radiographs. Thus, panoramic radiography does allow for the identification of sinus abnormalities. However, it may not be as reliable a method as $\mathrm{CBCT}$ based on the limitations of 2-D imaging: magnification, distortion, and superimposition [52]. It must be mentioned that the frequency of sinus mucosal thickening and retention cysts can vary due to odontogenic factors, age, gender, season, and presence of allergies [53,54]. As with airway findings, the importance of careful clinical correlation must be stressed when interpreting 3-D images of the paranasal sinuses, since minor opacification is a common finding, even in asymptomatic subjects [55,56]. 3-D imaging may provide information regarding the extent of the mucosal disease, but findings correlate poorly with clinical signs and symptoms [55-57]. Therefore, 3-D imaging may help to support a clinical diagnosis, but it should not be interpreted out of context.

\section{Dentoalveolar region}

There were 118 incidental findings (14.7\%) located in the dentoalveolar region, most commonly hypodontia (4.4\%). As mentioned, missing or non-developing third molars were not included as hypodontia in this study because it would inflate the number of findings, as it has been shown that the third molars are the most common congenitally missing tooth, with one or more missing in $9 \%$ to $20 \%$ of individuals [24]. In addition, due to the large range in age of our sample, in some subjects the third molar tooth germs would not yet be visible, while in others they may have been previously extracted. In the literature, opinions vary on the second most commonly missing tooth [58]. Some investigators [59-62] believe that it is the maxillary lateral incisor, whereas others $[63,64]$ believe that mandibular second premolar agenesis has a higher incidence. In our sample, of the total 37 congenitally missing teeth, 24 were second premolars (4.39\%), 11 were maxillary laterals (1.31\%), and 2 were mandibular central incisors $(0.24 \%)$. These rates are comparable but slightly less than rates described in the literature [65]. Other common dentoalveolar findings were dental impactions (3.33\%), idiopathic osteosclerosis (1.90\%), and supernumerary teeth $(0.71 \%)$. All of these findings can be readily identified in traditional 2-D imaging [66]. However, CBCT offers the advantage of more accurate localization [67] and assessment of adjacent structures [68], both of which have the potential to impact management decisions [69].

\section{Temporomandibular joint region}

There were 54 findings in the temporomandibular joint (TMJ) region, representing $6.4 \%$ of all findings. The main findings were physiologic remodeling (2.3\%), degenerative changes $(2.1 \%)$, and condylar hypoplasia (1.9\%). According to logistic regression analysis, when controlling for age, females were 2.55 times more likely to exhibit TMJ IFs than men $(P<0.001,95 \%$ CI $[1.29,5.03])$. This finding is commonly supported in the literature [14,22,70].

The decision was made to place condylar changes into two main categories, either physiologic remodeling or actual degenerative changes, even though the radiographic signs of mild degenerative joint disease (DJD) can be similar to those associated with joint remodeling. Isolated TMJ flattening and/or subcondral sclerosis was interpreted as physiologic remodeling, while condylar erosions and/or osteophyte formation was interpreted as active condylar degeneration (DJD). Pette et al. [14] and Allareddy et al. [21] reported higher rates of degenerative TMJ changes in patients receiving CBCT imaging primarily for dental implant assessment, identifying degenerative 
changes in $39.0 \%$ and $6.2 \%$ of patients, respectively, while other studies investigating orthodontic populations report degenerative TMJ changes in only $0.5 \%$ to $3.6 \%$ of subjects $[19,20]$. It has been demonstrated that the progression and severity of TMJ osseous changes are increased with advancing age [70,71]. This lower incidence of degenerative changes in our sample, and other orthodontic cohorts in the literature, is likely due to the nature of an orthodontic population, i.e., consisting primarily of adolescents.

\section{Cervical vertebrae region}

Cervical vertebral findings represented only $1.3 \%$ of all CBCT findings, a similar prevalence to other CBCT studies examining orthodontic populations $[17,20]$. This low rate of vertebral findings may be expected, given the low mean age of our orthodontic sample and variation in the number of vertebrae included in each of the scans. This is in contrast to CBCT studies by Pette et al. [14] and Allareddy et al. [21] which examined samples with much higher mean ages. In these studies, cervical vertebral findings were respectively identified in $47.8 \%$ and $9.7 \%$ of subjects, with the degenerative changes representing the main finding. Vertebral fusion was the most predominant finding in this region in our sample $(0.6 \%)$. The prevalence as demonstrated in other studies is $0.4 \%$ to $0.7 \%$ with no sex predilection, with $\mathrm{C} 2-\mathrm{C} 3$ being the most common location [72]. Generally, patients are asymptomatic, but increasing age or injury may precipitate symptoms as discal tear, rupture of the transverse ligament, and odontoid process fracture are common consequences. In addition to vertebral fusion, other findings have been identified in CBCT studies, including osteoarthritis, clefts, subchondral cysts, and osteophyte formation [14,20,21]. Many abnormalities of the cervical spine do not manifest themselves symptomatically until young adulthood, and if progressive degenerative defects are identified early, this may aid in the mitigation of the severity of their consequences [73]. With CBCT, the orthodontist and/or OMFR may be the first person to detect them and thus serve to screen and to refer for further assessment.

In our orthodontic sample, of the 842 reported findings, 718 (85.3\%) were located in extragnathic locations (i.e., outside the dentition and alveolus). This is comparable to similar CBCT studies in the literature. Price et al. [18], in a sample of 300 consecutive patients, reported a total of 881 incidental findings, with 775 (88.0\%) of these being extragnathic. In a sample of 318 dental implant patients, Pette et al. [14] reported that $93.7 \%$ of subjects had incidental extragnathic findings. They also identified both vascular and intracranial findings that were not reported in our sample. Internal carotid artery (ICA) calcifications were reported in $23.6 \%$ of their subjects and pineal gland calcification in $19.2 \%$ [14]. ICA calcifications were also identified in $5.7 \%$ of CBCT subjects by Allareddy et al. [21]. Similarly, ICA calcifications in CBCT were identified in $4.8 \%$ of subjects by Price et al. [18]. These findings were likely not identified in our sample due to major differences in mean age, as advanced age has been demonstrated to be a major risk factor for ICA calcification [74]. In panoramic imaging of large samples, Bayram et al. [75] and Kumagai et al. [76] respectively reported that ICA calcifications were identified in $2.1 \%$ and $4.0 \%$ of subjects. However, the presence of ICA calcifications does not always imply stenosis. The gold standard for the diagnosis of carotid artery stenosis (CAS) is duplex ultrasound and is utilized in cases of suspected CAS [77]. A number of studies have compared the incidence of ICA calcifications identified on panoramic radiography to CAS [77-80]. These studies, investigating populations over the age of 55, have observed positive ICA calcification in $2 \%$ to $5 \%$ of images [78-81]. Therefore, panoramic radiographs appear to be a valuable screening tool for CAS. However, due to the advantages of CBCT imaging (i.e., lack of overlapping structures, submillimeter voxel resolution, etc.), it may result in superior and more accurate screening for CAS. The relationship between ICA calcifications identified in CBCT imaging and CSA identified in duplex ultrasound must be further evaluated.

The frequency of IFs in CBCT imaging is much larger in number and in scope when compared to traditional 2-D imaging. Bondemark et al. [51] and Asaumi et al. [82] reported that incidental findings were respectively identified in only $8.7 \%$ and $6.1 \%$ of patients when panoramic radiographs were reviewed. Granlund et al. [66] reported an IF frequency of 2.2 IFs per panoramic image, a rate that is consistent with CBCT studies. However, in these three studies, there is no mention of airway, vascular, or cervical vertebral findings, presumably because these anatomic structures are poorly visible in panoramic imaging. Consequently, between $75.0 \%$ and $100 \%$ of the reported findings were confined within the dento-alveolus $[51,66,82]$, a region that dental clinicians should be competent in interpreting. This is in sharp contrast to CBCT studies.

\begin{tabular}{|c|c|c|}
\hline Anatomic location & $\begin{array}{c}\text { Incidental } \\
\text { findings, } n(\%)\end{array}$ & $\begin{array}{c}\text { Findings requiring } \\
\text { follow-up, } n(\%)\end{array}$ \\
\hline Cervical vertebrae & $11(1.3)$ & $1(0.1)$ \\
\hline Dentoalveolar & $124(14.7)$ & $19(2.3)$ \\
\hline Naso-oropharyngeal airway & $356(42.3)$ & $23(2.7)$ \\
\hline Paranasal sinuses & $260(30.9)$ & $22(2.6)$ \\
\hline Surrounding soft/hard tissues & $34(4.0)$ & $11(1.3)$ \\
\hline Temporomandibular joint & $54(6.4)$ & $18(2.1)$ \\
\hline Total & $842(100)$ & $94(11.2)$ \\
\hline
\end{tabular}




\section{Clinical significance}

Two fundamental matters are apparent upon review of the results, both relating to the clinical implications of the findings. Firstly, of clinical relevance is the percentage of IFs that require further follow-up and/or management from other medical/dental professionals, and secondly is how many IFs alter the orthodontic management of the patient. It must be stated that our study was based solely on radiographic interpretation, as no clinical information or other records were collected and/or considered. Therefore, inference into clinical significance is limited, specifically when relating to airway, sinus, and TMJ findings, as clinical signs/symptoms play an integral role in determining the presence and severity of disease. Thus, the researchers elected to categorize findings as significant, only if they required immediate follow-up. The authors determined by consensus that $11.2 \%(94 / 842)$ of findings required immediate follow-up based on radiographic appearance. The number of findings determined to require immediate follow-up based on anatomic category is listed in Table 4. Only adeno-tonsillar hypertrophy and sinus inflammation reported as severe by the OMFR were included as clinically significant. Examples of the most common significant findings include periapical rarefying osteitis, external root resorption, severe adeno-tonsillar hypertrophy, degenerative TMJ changes, and enlargement of sella turcica. Regarding our sample, it can be argued that the identification of four of the seven findings (Figures 3,4,6,9) recommended for follow-up by our OMFR may have been difficult using only 2-D imaging traditionally utilized in orthodontics.

It is difficult to discern the impact of these IFs on future orthodontic management in our sample. Several other studies have investigated the impact of CBCT findings on subsequent treatment planning decisions. Based on these, it is suggested that CBCT may provide more reliable information than 2-D images and that the interpretation of CBCT volumes may result in a different diagnosis and/or an alternative treatment plan for specific conditions such as root angulation, root resorption, third molar impaction, and canine impaction [69,83-87].

Only one study has investigated the impact of CBCT IFs on treatment decisions regarding subsequent orthodontic treatment planning. Drage et al. [20] determined that 45\% of IFs required further follow-up, but less than $1 \%$ of IFs were likely to influence orthodontic management. However, further investigations are needed to assess the impact of IFs on the management decisions made by clinicians and their impact on subsequent orthodontic treatment.

\section{Limitations}

There are several limitations with this descriptive crosssectional study. Only a single board-certified OMFR interpreted all CBCT scans. Thus, the interpretation reports are subject to reporter bias, with an unknown possibility of inconsistent diagnoses and errors. The subjective process of placing findings into anatomic categories can lead to differences when comparing studies in the literature. This is common when examining airway versus sinus findings, as some studies combined them into a single group, while they were separated in other studies, leading to either an under- or overestimation of findings for certain anatomic regions. Another inadequacy is that limited clinical and no prior radiographic or histological information was obtained to determine if the identified CBCT findings had been previously detected; this analysis was outside the scope of this study. Also, no clinical correlations of the findings were obtained as this study exclusively evaluated only the image data. Ideally, forthcoming research will investigate the impact of these findings on subsequent orthodontic management in terms of potential alteration of the treatment plant or the need for further multidisciplinary care.

\section{Conclusions}

This study confirms the high occurrence of incidental findings in large field-of-view maxillofacial CBCT scans in an orthodontic population. These findings suggest that the large majority are extragnathic findings, which can be normally considered outside the regions of interest and expertise of many dental clinicians. Specifically, incidental findings in the naso-oropharyngeal and paranasal air sinuses are the most frequent. This underscores the need for comprehensive review of the entire data volume and the requisite to properly document all findings, regardless of the region of interest.

\section{Competing interests}

The authors declare that they have no competing interests.

\section{Authors' contributions}

RE contributed to the conception and research design, acquisition of data, interpretation of data and drafted the manuscript. NA contributed to research design, interpretation of data, and drafting of the manuscript. GH contributed to analysis and interpretation of the data. CF contributed to the conception and research design, interpretation of data and drafting of the manuscript. All authors contributed to manuscript review, revisions and have approved the final manuscript.

\section{Author details}

${ }^{1}$ Orthodontic Graduate Program, Faculty of Medicine and Dentistry, University of Alberta, Edmonton, Alberta T6G 2R3, Canada. ${ }^{2}$ Department of Dentistry, Faculty of Medicine and Dentistry, University of Alberta, Edmonton, Alberta T6G 2R3, Canada.

Received: 7 January 2014 Accepted: 9 April 2014

Published online: 11 June 2014

\section{References}

1. Kapila S, Conley RS, Harrell WE. The current status of cone beam computed tomography imaging in orthodontics. Dentomaxillofal Rad. 2010; 40:24-34.

2. Honey OB, Scarfe WC, Hilgers MJ, Klueber K, Silveira AM, Haskell BS, Farman A. Accuracy of cone-beam computed tomography imaging of the temporomandibular joint: comparisons with panoramic radiology and linear tomography. Am J Orthod Dentofacial Orthop. 2007; 132:429-38. 
3. Hintze $\mathrm{H}$, Wiese $\mathrm{M}$, Wenzel $\mathrm{A}$. Cone beam $\mathrm{CT}$ and conventional tomography for the detection of morphological temporomandibular joint changes. Dentomaxillofac Rad. 2007; 36:192-7.

4. Becker A, Chaushu S, Casap-Caspi N. Cone-beam computed tomography and the orthosurgical management of impacted teeth. J Am Dent Assoc. 2010; 141(suppl 10):14S-8.

5. González-García R, Monje F. The reliability of cone-beam computed tomography to assess bone density at dental implant recipient sites: a histomorphometric analysis by micro-CT. Clin Oral Imp/ Res. 2013; 24:871-9. doi:10.1111/j.1600-0501.2011.02390.x.

6. Hatcher DC. Cone beam computed tomography: craniofacial and airway analysis. Dent Clin North Am. 2012; 56:343-57.

7. Popat H, Richmond S, Drage NA. New developments in: threedimensional planning for orthognathic surgery. J Orthod. 2010; 37:62-71.

8. Schneiderman ED, Xu H, Salyer KE. Characterization of the maxillary complex in unilateral cleft lip and palate using cone-beam computed tomography. J Craniofac Surg. 2009; 20(Suppl 2):1699-710.

9. Oberoi S, Knueppel S. Three-dimensional assessment of impacted canines and root resorption using cone beam computed tomography. Oral Surg Oral Med Oral Pathol Oral Radiol. 2012; 113:260-7.

10. Lombardo L, Bragazzi R, Perissinotto C, Mirabella D, Siciliani G. Cone-beam computed tomography evaluation of periodontal and bone support loss in extraction cases. Prog Orthod. 2013; 14:29.

11. Berland LL, Silverman SG, Gore RM, Mayo-Smith WW, Megibow AJ, Yee J, Brink JA, Baker ME, Federle MP, Foley WD, Francis IR, Herts BR, Isreal GM, Krinsky G, Platt JF, Shuman W, Taylor AJ. Managing incidental findings on abdominal $C T$ : white paper of the ACR Incidental Findings Committee. J Am Coll Radiol. 2010; 7:754-73.

12. Fletcher $\mathrm{RH}$, Pignone M. Extracolonic findings with computed tomographic colonography: asset or liability? Arch Intern Med. 2008; 168:685-6.

13. Edwards $R$, Altalibi M, Flores-Mir C. The frequency and nature of incidental findings in cone-beam computed tomographic scans of the head and neck region: a systematic review. J Am Dent Assoc. 2013; 144:161-70.

14. Pette GA, Norkin FJ, Ganeles J, Hardigan P, Lask E, Zfaz S, Parker W. Incidental findings from a retrospective study of 318 cone beam computed tomography consultation reports. Int J Oral Maxillofac Implants. 2012; 27:595-603.

15. Carter L, Farman AG, Geist J, Scarfe WC, Angelopoulos C, Nair MK, Hildebolt CF, Tyndall D, Shrout M. American academy of oral and maxillofacial radiology executive opinion statement on performing and interpreting diagnostic cone beam computed tomography. Oral Surg Oral Med Oral Pathol Oral Radiol Endod. 2008; 106:561-2.

16. Horner K, Islam M, Flygare L, Tsiklakis K, Whaites E. Basic principles for use of dental cone beam computed tomography: consensus guidelines of the European Academy of Dental and Maxillofacial Radiology. Dentomaxillofac Rad. 2009; 38:187-95.

17. Pliska B, Derocher $M$, Larson BE. Incidence of significant findings on CBCT scans of an orthodontic patient population. Northwest Dent. 2011; 90:13-6.

18. Price JB, Thaw KL, Tyndall DA, Ludlow JB, Padilla RJ. Incidental findings from cone beam computed tomography of the maxillofacial region: a descriptive retrospective study. (published online ahead of print Sept. 30, 2011). Clin Oral Implants Res. 2011; 23(11):1261-8. doi:10.1111/ j.1600-0501.2011.02299.x

19. Cha J, Mah J, Sinclair P. Incidental findings in the maxillofacial area with 3-dimensional cone-beam imaging. Am J Orthod Dentofacial Orthop. 2007; 132(1):7-14

20. Drage N, Rogers S, Greenall C, Playle R. Incidental findings on cone beam computed tomography in orthodontic patients. J Orthod. 2013; 40:29-37.

21. Allareddy V, Vincent SD, Hellstein JW, Qian F, Smoker WRK, Ruprecht A. Incidental findings on cone beam computed tomography images. Int J Dent. 2012; 9:1-9.

22. Rheem S, Nielsen IB, Oberoi S. Incidental findings in the maxillofacial region identified on cone-beam computed tomography scans. Journal of Orthod Res. 2013; 1:33-9.

23. Caglayan F, Tozoglu U. Incidental findings in maxillofacial region detected by cone beam computed tomography. Diagn Interv Radiol. 2012; 18:159-63.

24. Bishara SE, Andreasen G. Third molars: a review. Am J Orthod. 1983; 83:131-7.
25. Smith KD, Edwards PC, Saini TS, Norton NS. The prevalence of concha bullosa and nasal septal deviation and their relationship to maxillary sinusitis by volumetric tomography. Int J Dent. 2010; 2010:9-13.

26. Sazgar AA, Massah J, Sadeghi M, Bagheri A, Rasool E. The incidence of concha bullosa and the correlation with nasal septal deviation. B-ENT. 2008; 4:87-91.

27. Stallman JS, Lobo JN, Som PM. The incidence of concha bullosa and its relationship to nasal septal deviation and paranasal sinus disease. Am J Neuroradiol. 2004; 25:1613-8.

28. Bolger WE, Butzin CA, Parsons DS. Paranasal sinus bony anatomic variations and mucosal abnormalities: $\mathrm{CT}$ analysis for endoscopic sinus surgery. Laryngoscope. 1991; 101:56-64.

29. Hatipoglu HG, Cetin MA, Yuksel E. Nasal septal deviation and concha bullosa coexistence: CT evaluation. B-ENT. 2008; 4:227-32.

30. Flores-Mir C, Korayem M, Heo G, Witmans M, Major MP, Major PW. Craniofacial morphological characteristics in children with obstructive sleep apnea syndrome: a systematic review and meta-analysis. J Am Dent Assoc. 2013; 144:269-77.

31. Harvold EP, Tomer BS, Vargervik K, Chierici G. Primate experiments on oral respiration. Am J Orthod. 1981; 79(4):359-72.

32. Scarano E, Ottaviani F, Di Girolamo S, Galli A, Deli R, Paludetti G. Relationship between chronic nasal obstruction and craniofacial growth: an experimental model. Int J Pediatr Otorhinolaryngol. 1998; 45:125-31.

33. Arun T, Isik F, Sayinsu K. Vertical growth changes after adenoidectomy. Angle Orthod. 2003; 73:146-50.

34. Zettergren-Wijk L. Changes in dentofacial morphology after adenotonsillectomy in young children with obstructive sleep apnoea-a 5-year follow-up study. Eur J Orthodont. 2006; 28:319-26.

35. D'Ascanio L, Lancione C, Pompa G, Rebuffini E, Mansi N, Manzini M. Craniofacial growth in children with nasal septum deviation: a cephalometric comparative study. Int J Pediatr Otorhinolaryngol. 2010; 74:1180-3.

36. Moore M, Eccles R. Objective evidence for the efficacy of surgical management of the deviated septum as a treatment for chronic nasal obstruction: a systematic review. Clin Otolaryngol. 2011; 36:106-13.

37. Nathan RA. The pathophysiology, clinical impact, and management of nasal congestion in allergic rhinitis. Clin Ther. 2008; 30:573-86.

38. Egeli E, Demirci L, Yaz CB, Harputluoglu U. Evaluation of the inferior turbinate in patients with deviated nasal septum by using computed tomography. Laryngoscope. 2004; 114:113-7.

39. Farmer SEJ, Eccles R. Chronic inferior turbinate enlargement and the implications for surgical intervention. Rhinology. 2006; 44:234-8.

40. Ysunza A, Pamplona MC, Ortega JM, Prado H. Video fluoroscopy for evaluating adenoid hypertrophy in children. Int J Pediatr Otorhinolaryngol. 2008; 72:1159-65.

41. Major M. Accuracy and reliability of CBCT imaging for assessing adenoid hypertrophy. Canada: Masters Thesis University of Alberta; 2013: p. 1-104.

42. Yilmaz I, Caylakli F, Yilmazer C, Sener M, Ozluoglu LN. Correlation of diagnostic systems with adenoidal tissue volume: a blind prospective study. Int J Pediatr Otorhinolaryngol. 2008; 72:1235-40.

43. Lana JP, Carneiro PMR, Machado VC, de Souza PEA, Manzi FR, Horta MCR. Anatomic variations and lesions of the maxillary sinus detected in cone beam computed tomography for dental implants. Clin Oral Imp Res. 2011; 00:1-6. doi:10.1111/j.1600-0501.2011.02321.x

44. Havas TE, Motbey JA, Gullane PJ. Prevalence of incidental abnormalities on computed tomographic scans of the paranasal sinuses. Arch Otolaryngol Head Neck Surg. 1988; 114:856-9.

45. Diament MJ, Senac MO, Gilsanz V, Baker S, Gillespie T, Larsson S. Prevalence of incidental paranasal sinuses opacification in pediatric patients: a CT study. J Comput Assist Tomogr. 1987; 11:426-31.

46. Lim W-K, Ram B, Fasulakis S, Kane KJ. Incidental magnetic resonance image sinus abnormalities in asymptomatic Australian children. J Laryngol Otol. 2003; 117:969-72.

47. Gordts F, Clement P, Destryker A. Prevalence of sinusitis signs on MRI in a non-ENT paediatric population. Rhinology. 1997; 35:154-7.

48. Ritter L, Lutz J, Neugebauer J, Scheer M, Dreiseidler T, Zinser MJ, Rothamel D, Mischkowski R. Prevalence of pathologic findings in the maxillary sinus in cone-beam computerized tomography. Surg Oral Med Oral Pathol Oral Radiol Endod. 2011; 111:634-40.

49. Wang JH, Jang YJ, Lee B-J. Natural course of retention cysts of the maxillary sinus: long-term follow-up results. Laryngoscope. 2007; 117:341-4. 
50. Vallo J, Suominen-Taipale L, Huumonen S, Soikkonen K, Norblad A. Prevalence of mucosal abnormalities of the maxillary sinus and their relationship to dental disease in panoramic radiography: results from the Health 2000 Health Examination Survey. Oral Surg Oral Med Oral Pathol Oral Radiol Endod. 2010; 109:e80-7. doi:10.1016/ j.tripleo.2009.10.031.

51. Bondemark $L$, Jeppsson $M$, Lindh-Ingildsen $L$, Rangne $K$. Incidental findings of pathology and abnormality in pretreatment orthodontic panoramic radiographs. Angle Orthod. 2006; 76:98-102.

52. Scarfe WC, Farman AG. What is cone-beam CT and how does it work? Dent Clin North Am. 2008; 5:707-30.

53. Pazera $P$, Bornstein $M$, Pazera A, Sendi $P$, Katsaros $C$. Incidental maxillary sinus findings in orthodontic patients: a radiographic analysis using cone-beam computed tomography (CBCT). Orthod Craniofac Res. 2010; 14:17-24.

54. Carter LC, Calamel A, Haller A, Aguirre A. Seasonal variation in maxillary antral pseudocysts in a general clinic population. Dentomaxillofac Rad. 1998; 27:22-4

55. Jones NS. CT of the paranasal sinuses: a review of the correlation with clinical, surgical and histopathological findings. Clin Otolaryngol Allied Sci. 2002; 27:11-7.

56. Wani MK, Ruckenstein MJ, Parikh S. Magnetic resonance imaging of the paranasal sinuses: incidental abnormalities and their relationship to patient symptoms. J Otolaryngol. 2001; 30:257-62.

57. MCNeill E, O'Hara J, Carrie S. The significance of MRI findings for non-rhinological disease. Clin Otolaryngol. 2006; 31:292-6.

58. Vastardis $\mathrm{H}$. The genetics of human tooth agenesis: new discoveries for understanding dental anomalies. Am J Orthod Dentofacial Orthop. 2000; 117:650-6.

59. Malik SA. Missing and rudimentary upper lateral incisors: a statistical survey. J Dent. 1972; 1:25-7.

60. Muller T, Hill I, Peterson AC, Blayney JR. A survey of congenitally missing permanent teeth. J Am Dent Assoc. 1970; 81:101-7.

61. Baum BJ, Cohen MM. Studies on agenesis in the permanent dentition. Am J Phys Anthropol. 1971; 35:125-8.

62. Altug-Atac AT, Erdem D. Prevalence and distribution of dental anomalies in orthodontic patients. Am J Orthod Dentofacial Orthop. 2007; 131:510-4.

63. Hunstadbraten K. Hypodontia in the permanent dentition. ASDC J Dent Child. 1973; 40(2):115-7.

64. Grahnén H. Hypodontia in the permanent dentition: a clinical and genetical investigation. Odont Revy. 1956; 7:1-100.

65. Symons AL, Stritzel F, Stamation J. Anomalies associated with hypodontia of the permanent lateral incisor and second premolar. J Clin Pediatr Dent. 1993; 17:109-11.

66. Granlund CM, Lith A, Molander B, Grondahl K, Hansen K, Ekestubbe A. Frequency of errors and pathology in panoramic images of young orthodontic patients. Eur J Orthod. 2012; 34:452-7.

67. Liu DG, Zhang WL, Zhang ZY, Wu YT, Ma XC. Localization of impacted maxillary canines and observation of adjacent incisor resorption with cone-beam computed tomography. Oral Surg Oral Med Oral Pathol Oral Radiol Endod. 2008; 105:91-8.

68. Liu D-G, Zhang W-L, Zhang Z-Y, Wu Y-T, Ma X-C. Localization of impacted maxillary canines and observation of adjacent incisor resorption with cone-beam computed tomography. Oral Surg Oral Med Oral Pathol Oral Radiol Endod. 2008; 105(1):91-8.

69. Haney E, Gansky SA, Lee JS, Johnson E, Maki K, Miller AJ, Huang JC. Comparative analysis of traditional radiographs and cone-beam computed tomography volumetric images in the diagnosis and treatment planning of maxillary impacted canines. Am J Orthod Dentofacial Orthop. 2010; 137:590-7.

70. Anjos Pontual dos M, Freire J, Barbosa J, Frazao M, Anjos Pontual dos A, Fonseca da Silveira M. Evaluation of bone changes in the temporomandibular joint using cone beam CT. Dentomaxillofac Rad. 2011; 41:24-9.

71. Alexiou K, Stamatakis H, Tsiklakis K. Evaluation of the severity of temporomandibular joint osteoarthritic changes related to age using cone beam computed tomography. Dentomaxillofac Rad. 2009; 38:141-7.

72. Bebnowski D, Hanggi MP, Markic G, Roos M, Peltomaki T. Cervical vertebrae anomalies in subjects with class II malocclusion assessed by lateral cephalogram and cone beam computed tomography. Eur J Orthod. 2012; 34:226-31.
73. Soni P, Sharma V, Sengupta J. Cervical vertebrae anomalies-incidental findings on lateral cephalograms. Angle Orthod. 2008; 78:176-80.

74. Bos D, van der Rijk MJM, Geeraedts TEA, Hofman A, Krestin GP, Witteman JCM, van der Lugt A, Ikram MA, Vernooij MW. Intracranial carotid artery atherosclerosis: prevalence and risk factors in the general population. Stroke. 2012; 43:1878-84.

75. Bayram B, Uckan S, Acikgoz A, Müderrisoglu H, Aydinalp A. Digital panoramic radiography: a reliable method to diagnose carotid artery atheromas? Dentomaxillofac Rad. 2006; 35:266-70.

76. Kumagai M, Yamagishi T, Fukui N, Chiba M. Carotid artery calcification seen on panoramic dental radiographs in the Asian population in Japan. Dentomaxillofac Rad. 2007; 36:92-6.

77. Almog DM, Horev T, Illig KA, Green RM, Carter LC. Correlating carotid artery stenosis detected by panoramic radiography with clinically relevant carotid artery stenosis determined by duplex ultrasound. Oral Surg Oral Med Oral Pathol Oral Radiol Endod. 2002; 94:768-73.

78. Friedlander $\mathrm{AH}$, Lande $\mathrm{A}$. Panoramic radiographic identification of carotid arterial plaques. Oral Surg Oral Med Oral Pathol. 1981; 52:102-4.

79. Friedlander AH, Manesh F, Wasterlain CG. Prevalence of detectable carotid artery calcifications on panoramic radiographs of recent stroke victims. Oral Surg Oral Med Oral Pathol Oral Radiol Endod. 1994; 77:669-73.

80. Carter $L C$, Haller AD, Nadarajah V. Use of panoramic radiography among an ambulatory dental population to detect patients at risk of stroke. J Am Dent Assoc. 1997; 128:977-84.

81. Almog DM A, Illig KA, Khin M, Green RM. Unrecognized carotid artery stenosis discovered by calcifications on a panoramic radiograph. J Am Dent Assoc. 2000; 131:1593-7.

82. Asaumi J-I, Hisatomi M, Yanagi $Y$, Unetsubo T, Maki $Y$, Matsuzaki H, Honda $Y$, Konouchi $\mathrm{H}$. Evaluation of panoramic radiographs taken at the initial visit at a department of paediatric dentistry. Dentomaxillofac Rad. 2008; 37:340-3.

83. Alqerban A, Jacobs R, Souza PC, Willems G. In-vitro comparison of 2 cone-beam computed tomography systems and panoramic imaging for detecting simulated canine impaction-induced external root resorption in maxillary lateral incisors. Am J Orthod Dentofacial Orthop. 2009; 136:764. e1-764.e11.

84. Dudic A, Giannopoulou C, Leuzinger M, Kiliaridis S. Detection of apical root resorption after orthodontic treatment by using panoramic radiography and cone-beam computed tomography of super-high resolution. Am J Orthod Dentofacial Orthop. 2009; 135:434-7.

85. Alqerban A, Jacobs R, Fieuws S, Willems G. Comparison of two cone beam computed tomographic systems versus panoramic imaging for localization of impacted maxillary canines and detection of root resorption. The Euro J of Ortho. 2011; 33:93-102.

86. Bouwens DG, Cevidanes L, Ludlow JB, Phillips C. Comparison of mesiodistal root angulation with posttreatment panoramic radiographs and cone-beam computed tomography. Am J Orthod Dentofacial Orthop. 2011; 139:126-32.

87. Ghaeminia H, Meijer GJ, Soehardi A, Borstlap WA, Mulder J, Vlijmen OJC, Berge SJ, Maal TJJ. The use of cone beam CT for the removal of wisdom teeth changes the surgical approach compared with panoramic radiography: a pilot study. Int J Oral Maxillofac Surg. 2011; 40:834-9.

doi:10.1186/s40510-014-0037-x

Cite this article as: Edwards et al:: The frequency and nature of incidental findings in large-field cone beam computed tomography scans of an orthodontic sample. Progress in Orthodontics 2014 15:37. 